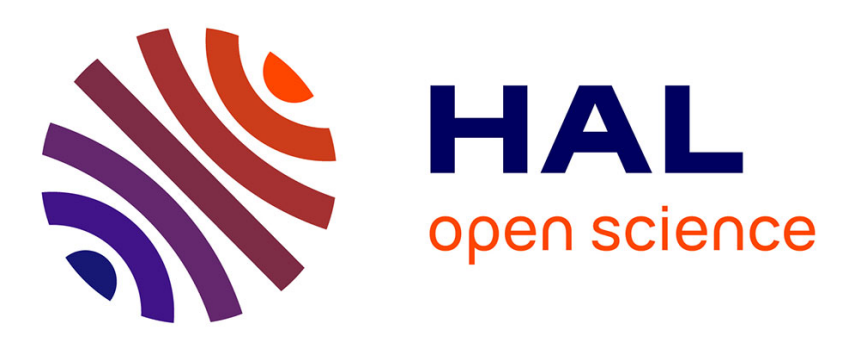

\title{
Si Isotope Homogeneity of the Solar Nebula
}

Emily A. Pringle, Paul S. Savage, Matthew G. Jackson, Jean-Alix J-A Barrat, Frédéric Moynier

\section{To cite this version:}

Emily A. Pringle, Paul S. Savage, Matthew G. Jackson, Jean-Alix J-A Barrat, Frédéric Moynier. Si Isotope Homogeneity of the Solar Nebula. The Astrophysical Journal, 2013, 779, pp.123. 10.1088/0004637X/779/2/123 . insu-00918191

\section{HAL Id: insu-00918191 https://hal-insu.archives-ouvertes.fr/insu-00918191}

Submitted on 13 Dec 2013

HAL is a multi-disciplinary open access archive for the deposit and dissemination of scientific research documents, whether they are published or not. The documents may come from teaching and research institutions in France or abroad, or from public or private research centers.
L'archive ouverte pluridisciplinaire HAL, est destinée au dépôt et à la diffusion de documents scientifiques de niveau recherche, publiés ou non, émanant des établissements d'enseignement et de recherche français ou étrangers, des laboratoires publics ou privés. 


\title{
Si ISOTOPE HOMOGENEITY OF THE SOLAR NEBULA
}

\author{
Emily A. Pringle ${ }^{1,2}$, Paul S. Savage ${ }^{1}$, Matthew G. Jackson ${ }^{3}$, Jean-Alix Barrat ${ }^{4}$, and Frédéric Moynier ${ }^{1,2}$ \\ ${ }^{1}$ Department of Earth and Planetary Sciences and McDonnell Center for the Space Sciences, \\ Washington University in St. Louis, One Brookings Drive, St. Louis, MO 63130, USA; eapringle@wustl.edu, savage@ levee.wustl.edu \\ ${ }^{2}$ Institut de Physique du Globe de Paris, Université Paris Diderot, 75005 Paris, France; pringle@ipgp.fr, moynier@ipgp.fr \\ ${ }^{3}$ Department of Earth Science, University of California, Santa Barbara, CA 93109, USA; jackson@ geol.ucsb.edu \\ ${ }^{4}$ Université Européenne de Bretagne, Université de Brest, CNRS UMR 6538 (Domaines Océaniques), \\ I.U.E.M., Place Nicolas Copernic, F-29280 Plouzané Cedex, France; Jean-Alix.Barrat@univ-brest.fr \\ Received 2013 July 18; accepted 2013 October 15; published 2013 December 2
}

\begin{abstract}
The presence or absence of variations in the mass-independent abundances of $\mathrm{Si}$ isotopes in bulk meteorites provides important clues concerning the evolution of the early solar system. No $\mathrm{Si}$ isotopic anomalies have been found within the level of analytical precision of $15 \mathrm{ppm}$ in ${ }^{29} \mathrm{Si} /{ }^{28} \mathrm{Si}$ across a wide range of inner solar system materials, including terrestrial basalts, chondrites, and achondrites. A possible exception is the angrites, which may exhibit small excesses of ${ }^{29} \mathrm{Si}$. However, the general absence of anomalies suggests that primitive meteorites and differentiated planetesimals formed in a reservoir that was isotopically homogenous with respect to $\mathrm{Si}$. Furthermore, the lack of resolvable anomalies in the calcium-aluminum-rich inclusion measured here suggests that any nucleosynthetic anomalies in $\mathrm{Si}$ isotopes were erased through mixing in the solar nebula prior to the formation of refractory solids. The homogeneity exhibited by Si isotopes may have implications for the distribution of $\mathrm{Mg}$ isotopes in the solar nebula. Based on supernova nucleosynthetic yield calculations, the expected magnitude of heavy-isotope overabundance is larger for $\mathrm{Si}$ than for $\mathrm{Mg}$, suggesting that any potential $\mathrm{Mg}$ heterogeneity, if present, exists below the $15 \mathrm{ppm}$ level.
\end{abstract}

Key words: astrochemistry - minor planets, asteroids: general - nuclear reactions, nucleosynthesis, abundances planets and satellites: formation - protoplanetary disks

Online-only material: color figures

\section{INTRODUCTION}

Primitive meteorites (chondrites) are the remnants of the first planetary bodies to accrete in the solar system. Variations in the relative abundances of an element's isotopes in meteorites provide important information about the pre-solar chemical environment and the physical processes governing the formation and evolution of the solar system. The large majority of mass-independent isotopic variations (i.e., isotopic variations after correction for traditional thermodynamic isotopic fractionation, in which the amount of fractionation scales in proportion to the mass difference between isotopes) at the bulk-meteorite scale have been attributed to incomplete mixing of two (or more) isotopically distinct nucleosynthetic reservoirs within the solar nebula (Birck 2004; Warren 2011; Fitoussi \& Bourdon 2012; Moynier et al. 2012); however, some variations have also been attributed to chemical fractionation (Clayton 2002; Moynier et al. 2013). In contrast, a lack of isotopic anomalies in bulk meteorites would suggest the complete homogenization of any distinct nucleosynthetic components, which resulted in a uniform early reservoir prior to planetesimal accretion. Such homogenization has previously been suggested by analysis of several elements at the bulk-rock scale, including Fe and Zn (Dauphas et al. 2008; Moynier et al. 2009; Wang et al. 2011; Tang \& Dauphas 2012).

Of the light elements, $\mathrm{O}, \mathrm{S}$, and Ca show mass-independent fractionation in bulk meteorites (Clayton 1993; Rai et al. 2005; Rai \& Thiemens 2007; Simon et al. 2009). However, the interpretation of $\mathrm{O}$ isotope anomalies is debated; variations may not reflect initial heterogeneity in the solar nebula since other mechanisms for mass-independent $\mathrm{O}$ isotope fractionation have been identified (Thiemens 1999; Clayton 2002; Yurimoto \&
Kuramoto 2004; Lyons \& Young 2005). After O and Mg, Si is the third lightest element with the three stable isotopes needed to determine mass-independent effects, and $\mathrm{Si}$ is a major element in the terrestrial planets.

Silicon is composed of three stable isotopes: ${ }^{28} \mathrm{Si}(92.23 \%)$, ${ }^{29} \mathrm{Si}(4.68 \%)$, and ${ }^{30} \mathrm{Si}(3.09 \%)$. The most abundant isotope, ${ }^{28} \mathrm{Si}$, is a principle product of oxygen burning in massive stars, and is produced in core-collapse supernovae and, to a lesser extent, Type Ia supernovae (Timmes \& Clayton 1996). The two heavier stable isotopes of $\mathrm{Si},{ }^{29} \mathrm{Si}$ and ${ }^{30} \mathrm{Si}$, are secondary nucleosynthesis products and are mainly produced during carbon burning through the reaction of an $\alpha$ particle with ${ }^{25} \mathrm{Mg}$ and ${ }^{26} \mathrm{Mg}$, respectively. Another production source of ${ }^{29} \mathrm{Si}$ and ${ }^{30} \mathrm{Si}$ is $s$-process neutron capture during He burning in asymptotic giant branch (AGB) stars.

Large $\mathrm{Si}$ isotopic anomalies are found in various types of presolar grains (Zinner et al. 2006; Lewis et al. 2013), and in fact the presence of $\mathrm{Si}$ isotope abundances that are significantly different than solar Si ratios is one identifying characteristic of a presolar grain. These anomalies have been attributed to distinct nucleosynthetic sources of Si that condensed prior to the collapse of the solar nebula and therefore retained their individual isotopic signatures (Lodders \& Amari 2005). However, the extent to which such reservoirs were mixed during nebular collapse remains open for debate. The isotopic analysis of bulk meteorites can provide information about the level of homogenization of material within the solar nebula. Early searches for $\mathrm{Si}$ isotopic anomalies in bulk meteorites found only massdependent isotope fractionation (Molini-Velsko et al. 1986), but advances in Multi-Collector Inductively-Coupled-Plasma MassSpectrometery (MC-ICP-MS) have improved analytical precision by a factor of three. The current level of precision of $15 \mathrm{ppm}$ 
Table 1

Silicon Isotopic Compositions of Terrestrial Samples

\begin{tabular}{llrrr}
\hline \hline Sample & \multicolumn{1}{c}{ Location } & $\varepsilon^{29} \mathrm{Si}$ & $2 \mathrm{se}$ & $n$ \\
\hline Terrestrial standard & & & & \\
BHVO-2 & & -0.02 & 0.06 & 115 \\
OIB & & & \\
OFU-04-14 & Samoa-Ofu & -0.11 & 0.12 & 10 \\
ALIA-115-03 & Samoa-Savai'i & -0.15 & 0.25 & 6 \\
ALIA-115-18 & Samoa-Savai'i & -0.08 & 0.12 & 6 \\
T16 & Samoa-Ta'u & -0.10 & 0.22 & 6 \\
T38 & Samoa-Ta'u & -0.06 & 0.10 & 6 \\
63-2 & Samoa-Vailulu'u & -0.21 & 0.08 & 6 \\
76-9 & Samoa-Malumalu & 0.14 & 0.14 & 6 \\
78-1 & Samoa-Malumalu & -0.06 & 0.19 & 6 \\
128-21 & Samoa-Taumatau & 0.12 & 0.19 & 6 \\
PIT 1 & Pitcairn & 0.04 & 0.09 & 6 \\
PIT 3 & Pitcairn & 0.03 & 0.16 & 6 \\
PIT 4A & Pitcairn & 0.04 & 0.19 & 6 \\
PIT 6 & Pitcairn & -0.12 & 0.23 & 6 \\
PIT 8 & Pitcairn & 0.08 & 0.12 & 6 \\
PIT 16 & Pitcairn & 0.02 & 0.21 & 6 \\
Average-terrestrial & & -0.03 & 0.05 & 16 \\
\hline
\end{tabular}

$(2 \sigma)$ has made it possible to refine the search for inherited presolar nucleosynthetic heterogeneities that were preserved during accretion in the solar nebula.

This study presents high-precision $\mathrm{Si}$ isotopic measurements on a wide range of terrestrial and meteorite samples in order to quantify possible heterogeneities in $\mathrm{Si}$ isotope composition at the bulk-rock scale. At the current level of precision, $\mathrm{Si}$ isotopes display widespread homogeneity across bulk solar system materials, suggesting that inherited $\mathrm{Si}$ isotopic anomalies were erased through mixing in the solar nebula prior to planetary accretion. A possible exception is the angrites, which may exhibit small excesses of ${ }^{29} \mathrm{Si}$. We discuss the implications of these results on the distribution of $\mathrm{Mg}$ isotopes.

\section{SAMPLES AND ANALYTICAL PROCEDURES}

This study reports the $\mathrm{Si}$ isotopic composition of a wide range of bulk solar system materials, including chondritic meteorites (5 ordinary chondrites, 8 carbonaceous chondrites, 6 enstatite $\mathrm{H}$ chondrites, and 7 enstatite L chondrites), achondritic meteorites (6 martian meteorites, 2 howardites, 9 eucrites, 3 diogenites, 5 angrites), and 16 terrestrial basalts. Achondrites represent the differentiated silicate fraction of planetary bodies. The achondrite samples reported here are believed to represent Mars, the asteroid 4-Vesta (in the case of the howardites, eucrites, and diogenites), and the angrite parent body. The terrestrial basalts include Ocean Island Basalts (OIBs) from Pitcairn and Samoa, which are locations representative of different mantle sources (EM1 and EM2, respectively; Hofmann 1997). The Si isotopic composition of a Calcium-Aluminum-rich Inclusion (CAI) from the Allende carbonaceous chondrite is also reported.

The sample dissolution and chemical purification methods used are as described in previous $\mathrm{Si}$ isotope studies at Washington University in St. Louis (Pringle et al. 2013; Savage \& Moynier 2013). Powdered samples were dissolved in $\mathrm{Ag}$ crucibles using a $\mathrm{NaOH}$ alkali fusion technique and subsequently purified for $\mathrm{Si}$ isotope analysis through ion-exchange chromatography using BioRad AG50 X-12 (200-400 mesh) cation exchange resin, following the procedure developed by Georg et al. (2006).
Table 2

Silicon Isotopic Compositions of Chondrites and Refractory Inclusions

\begin{tabular}{|c|c|c|c|c|}
\hline Sample & Type & $\varepsilon^{29} \mathrm{Si}$ & $2 \mathrm{se}$ & $n$ \\
\hline \multicolumn{5}{|l|}{ Chondrites } \\
\hline \multicolumn{5}{|l|}{ Ordinary chondrites } \\
\hline Hallingeberg & L3.4 & -0.06 & 0.37 & 6 \\
\hline Saratov & L4 & 0.12 & 0.19 & 7 \\
\hline Tadjera & L5 & 0.20 & 0.20 & 7 \\
\hline L'Aigle & L6 & 0.22 & 0.11 & 6 \\
\hline Parnallee & LL3.6 & 0.01 & 0.18 & 13 \\
\hline Olivenza & LL5 & -0.11 & 0.41 & 6 \\
\hline Cherokee Springs & LL6 & 0.20 & 0.18 & 6 \\
\hline Average-ordinary chondrites & & 0.08 & 0.10 & 7 \\
\hline \multicolumn{5}{|l|}{ Carbonaceous chondrites } \\
\hline Orgueil & CI1 & 0.07 & 0.12 & 16 \\
\hline Cold Bokkeveld & $\mathrm{CM} 2$ & -0.07 & 0.11 & 22 \\
\hline Murchison & CM2 & -0.14 & 0.12 & 10 \\
\hline Ornans \#1 & $\mathrm{CO} 3.4$ & -0.10 & 0.12 & 12 \\
\hline Ornans \#2 & $\mathrm{CO} 3.4$ & 0.03 & 0.11 & 12 \\
\hline Average-Ornans & & -0.04 & & 2 \\
\hline Lancé & $\mathrm{CO} 3.5$ & 0.01 & 0.17 & 12 \\
\hline Isna & $\mathrm{CO} 3.8$ & -0.17 & 0.18 & 10 \\
\hline Allende & CV3 & -0.01 & 0.09 & 38 \\
\hline Vigarano & CV3 & 0.07 & 0.14 & 11 \\
\hline Average-carbonacous chondrites & & -0.03 & 0.06 & 8 \\
\hline \multicolumn{5}{|l|}{ EH chondrites } \\
\hline Qingzhen & EH3 & 0.02 & 0.19 & 13 \\
\hline GRO95517 & EH3 & 0.29 & 0.23 & 9 \\
\hline Sahara 97076 & $\mathrm{EH} 3$ & -0.05 & 0.10 & 6 \\
\hline Abee & $\mathrm{EH} 4$ & 0.03 & 0.13 & 14 \\
\hline Indarch & EH4 & 0.10 & 0.29 & 13 \\
\hline St. Marks & EH5 & -0.08 & 0.21 & 12 \\
\hline Average-EH chondrites & & 0.05 & 0.11 & 6 \\
\hline \multicolumn{5}{|l|}{ EL chondrites } \\
\hline MAC 88184 & EL3 & -0.06 & 0.24 & 11 \\
\hline Atlanta & EL6 & 0.08 & 0.22 & 12 \\
\hline Hvittis & EL6 & 0.21 & 0.14 & 8 \\
\hline Blithfield & EL6 & 0.47 & 0.32 & 3 \\
\hline Eagle & EL6 & -0.06 & 0.12 & 9 \\
\hline Khairpur & EL6 & 0.13 & 0.24 & 12 \\
\hline LON 94100 & EL6 & 0.16 & 0.20 & 8 \\
\hline Average-EL chondrites & & 0.13 & 0.14 & 7 \\
\hline \multicolumn{5}{|l|}{ Refractory Inclusions } \\
\hline Allende CAI & & -0.10 & 0.20 & 9 \\
\hline
\end{tabular}

Silicon isotope compositions were measured on a Thermo Scientific Neptune Plus MC-ICP-MS at Washington University in St. Louis, operating in medium resolution mode. Measurements were made using standard-sample bracketing with the quartz sand standard NBS28 (NIST RM8546) subjected to the same $\mathrm{Si}$ purification procedure as the samples.

\section{RESULTS}

Silicon isotopic data are given in Tables $1-3$ and Figure 1 in epsilon units (deviation in parts per 10,000 relative to the NBS28 standard; Equation (1)) after internal normalization to a ${ }^{30} \mathrm{Si} /{ }^{28} \mathrm{Si}$ ratio of 0.03347 using an exponential law (Maréchal et al. 1999),

$$
\varepsilon^{29} \mathrm{Si}=\left(\frac{\left({ }^{29} \mathrm{Si} /{ }^{28} \mathrm{Si}\right)_{\text {sample }}}{\left({ }^{29} \mathrm{Si} /{ }^{28} \mathrm{Si}\right)_{\mathrm{NBS} 28}}-1\right) 10^{4}
$$


Table 3

Silicon Isotopic Compositions of Achondrites

\begin{tabular}{|c|c|c|c|c|}
\hline Sample & Group & $\varepsilon^{29} \mathrm{Si}$ & $2 \mathrm{se}$ & $n$ \\
\hline \multicolumn{5}{|l|}{ Martian meteorites } \\
\hline Sayh al Uhaymir 008 & Shergottite & 0.14 & 0.22 & 7 \\
\hline Los Angeles & Shergottite & -0.05 & 0.16 & 10 \\
\hline Miller Range 03346 & Nakhlite & 0.18 & 0.17 & 6 \\
\hline Lafayette & Nakhlite & 0.09 & 0.12 & 6 \\
\hline Nakhla & Nakhlite & -0.03 & 0.20 & 6 \\
\hline Allan Hills 84001 & Orthopyroxenite & -0.05 & 0.30 & 7 \\
\hline Average-Martin meteorites & & 0.05 & 0.08 & 6 \\
\hline \multicolumn{5}{|l|}{$H E D$} \\
\hline Kapoeta & Howardite & -0.11 & 0.24 & 6 \\
\hline Frankfort & Howardite & 0.18 & 0.18 & 5 \\
\hline Serra de Magé & Eucrite & -0.02 & 0.22 & 6 \\
\hline Petersburg & Eucrite & -0.07 & 0.17 & 6 \\
\hline Cachari \#1 & Eucrite & -0.04 & 0.44 & 6 \\
\hline Cachari \#2 & Eucrite & 0.26 & 0.19 & 7 \\
\hline Average-Cachari & & 0.11 & & 2 \\
\hline Camel Donga & Eucrite & -0.03 & 0.26 & 6 \\
\hline Jonzac & Eucrite & 0.26 & 0.30 & 6 \\
\hline Juvinas & Eucrite & 0.18 & 0.17 & 5 \\
\hline Bouvante \#1 & Eucrite & 0.02 & 0.26 & 6 \\
\hline Bouvante \#2 & Eucrite & 0.08 & 0.29 & 7 \\
\hline Average-Bouvante & & 0.05 & & 2 \\
\hline Stannern \#1 & Eucrite & 0.00 & 0.26 & 6 \\
\hline Stannern \#2 & Eucrite & 0.01 & 0.21 & 5 \\
\hline Average-Stannern & & 0.01 & & 2 \\
\hline Pomozdino & Eucrite & 0.34 & 0.37 & 6 \\
\hline Aioun el Atrouss & Diogenite & 0.04 & 0.21 & 6 \\
\hline Tatahouine & Diogenite & 0.08 & 0.25 & 6 \\
\hline Shalka & Diogenite & 0.15 & 0.12 & 6 \\
\hline Average-HED meteorites & & 0.08 & 0.07 & 14 \\
\hline \multicolumn{5}{|l|}{ Angrites } \\
\hline D’Orbigny & & 0.27 & 0.14 & 12 \\
\hline NWA1296 & & 0.20 & 0.16 & 10 \\
\hline NWA2999 & & 0.05 & 0.13 & 10 \\
\hline NWA4590 & & 0.32 & 0.12 & 10 \\
\hline NWA4931 & & 0.13 & 0.15 & 10 \\
\hline Average-Angrites & & 0.18 & 0.10 & 5 \\
\hline
\end{tabular}

Errors cited are the 2 standard error (2 se; calculated as 2 standard deviation $/ \sqrt{ } n$ ) unless otherwise stated.

Table 1 reports the $\mathrm{Si}$ isotopic compositions of the terrestrial basalts; both the replicate analyses of the basalt standard BHVO-2 $\left(\varepsilon^{29} \mathrm{Si}=-0.02 \pm 0.06,2 \mathrm{se}, n=115\right.$ measurements $)$ and the combined average of all terrestrial samples analyzed $\left(\varepsilon^{29} \mathrm{Si}=-0.03 \pm 0.05,2\right.$ se, $\left.n=16\right)$ are comparable to NBS28, suggesting that NBS28 is representative of a welldefined terrestrial $\mathrm{Si}$ isotopic composition. The group averages of all meteorite samples measured (with the exception of the angrites, discussed below) have $\mathrm{Si}$ isotopic compositions that are indistinguishable from the terrestrial average.

The Si isotopic data for the chondrites and the Allende CAI are reported in Table 2. On average, the carbonaceous chondrites $\left(\varepsilon^{29} \mathrm{Si}=-0.03 \pm 0.06,2\right.$ se, $\left.n=8\right)$, ordinary chondrites $\left(\varepsilon^{29} \mathrm{Si}=0.08 \pm 0.10,2\right.$ se, $\left.n=7\right)$, enstatite EH chondrites $\left(\varepsilon^{29} \mathrm{Si}=0.05 \pm 0.11,2 \mathrm{se}, n=6\right)$, and enstatite EL chondrites $\left(\varepsilon^{29} \mathrm{Si}=0.13 \pm 0.14,2\right.$ se, $\left.n=7\right)$ all have $\mathrm{Si}$ isotopic compositions similar to terrestrial. The $\mathrm{Si}$ isotopic composition of the Allende CAI is also comparable to the terrestrial value within error $\left(\varepsilon^{29} \mathrm{Si}=-0.10 \pm 0.20,2 \mathrm{se}, n=9\right)$.

Table 3 gives the $\mathrm{Si}$ isotope data for the achondrites measured in this study. The martian meteorite average $\left(\varepsilon^{29} \mathrm{Si}=0.05 \pm\right.$

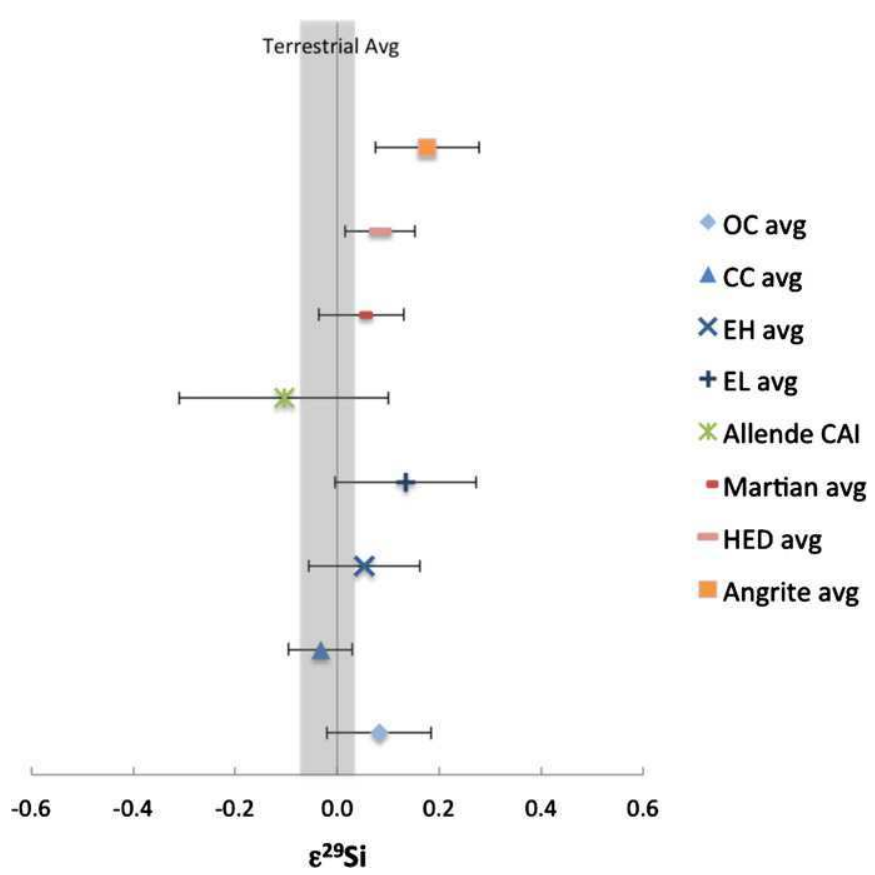

Figure 1. Silicon isotopic compositions of terrestrial samples, bulk meteorites, and an Allende CAI. Data are given in $\varepsilon^{29} \mathrm{Si}$ (parts per 10,000) after internal normalization. Error bars represent the 2 standard error. The shaded box represents the average $\mathrm{Si}$ isotopic composition of all terrestrial samples measured $( \pm 2 \mathrm{se})$. Most planetary materials are within error of terrestrial composition, suggesting the homogeneous distribution of $\mathrm{Si}$ isotopes in the solar system.

(A color version of this figure is available in the online journal.)

$0.08,2$ se, $n=6$ ) is not resolvable from terrestrial $\mathrm{Si}$ isotopic composition at the current level of analytical precision. The Howardite-Eucrite-Diogenite (HED) meteorite group average falls within the terrestrial range but is very slightly offset from $\varepsilon^{29} \mathrm{Si}=0$ within $2 \mathrm{se}\left(\varepsilon^{29} \mathrm{Si}=0.08 \pm 0.07, n=14\right)$; however, as no systematic variation is apparent, this is likely a result of an error underestimation. Finally, all the angrite samples have consistent ${ }^{29} \mathrm{Si}$ excesses (on average, $\varepsilon^{29} \mathrm{Si}=0.18 \pm 0.10,2 \mathrm{se}$, $n=5$ ), suggesting a small non-linear isotopic effect. Taken together, all the sample groups (excluding angrites) give an average $\varepsilon^{29} \mathrm{Si}$ value of $0.06 \pm 0.14$ ( 2 standard deviation). We consider this error of $\sim 15$ ppm (i.e., 0.15 epsilon units) in ${ }^{29} \mathrm{Si} /{ }^{28} \mathrm{Si}$ after internal normalization as representative of the analytical precision for the present study.

\section{DISCUSSION}

The lack of any resolvable $\mathrm{Si}$ isotopic anomalies within the current level of precision at the bulk-rock scale in either primitive chondrites or meteorites derived from differentiated parent bodies (with the exception of angrites, see below) suggests that any inherited nucleosynthetic variations in $\mathrm{Si}$ isotopes were erased through mixing in the solar nebula prior to the formation of planetesimals. Therefore, the Si isotopic compositions of the different planetary bodies in the inner solar system represent a well-mixed average of different stellar sources. Furthermore, the single Allende CAI analyzed here has a $\mathrm{Si}$ isotopic composition that is indistinguishable from bulk chondrites and terrestrial samples, suggesting that the homogenization of $\mathrm{Si}$ isotopes occurred at the mineral scale as early as the age of the CAIs (4.567-4.568 Ga; Bouvier et al. 2007; Jacobsen et al. 2008; Bouvier \& Wadhwa 2010). 


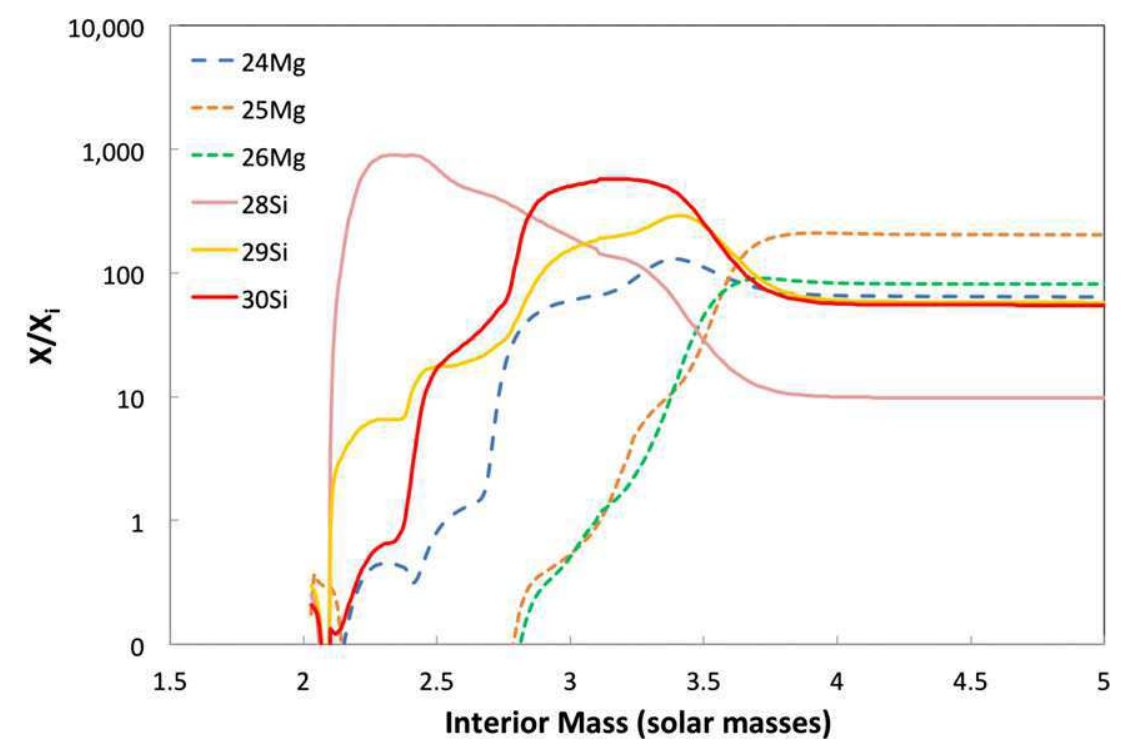

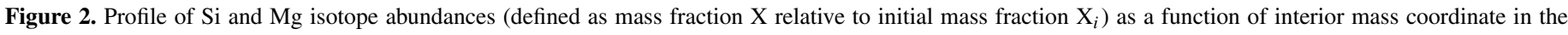
supernova ejecta of the stellar model s25a37j of Rauscher et al. (2002).

(A color version of this figure is available in the online journal.)

The homogeneous distribution of $\mathrm{Si}$ isotopes has important implications for the distribution of $\mathrm{Mg}$ isotopes in the solar nebula. The presence of anomalies in $\mathrm{Mg}$ isotope abundances would have consequences for the ${ }^{26} \mathrm{Al}-{ }^{26} \mathrm{Mg}$ short-lived isotope system $\left(\mathrm{t}_{1 / 2}=0.73 \mathrm{Myr}\right)$, which is a principal chronometer for dating accretion and differentiation events in the early solar system (Jacobsen et al. 2008; Villeneuve et al. 2009; Schiller et al. 2010). A heterogeneous distribution of $\mathrm{Mg}$ isotopes in the pre-solar disk that was preserved in solar system materials during planetary accretion could lead to erroneous ${ }^{26} \mathrm{Al}-{ }^{26} \mathrm{Mg}$ model ages. Larsen et al. (2011) found heterogeneities in the ${ }^{26} \mathrm{Mg}$ excesses $\left(\delta^{26} \mathrm{Mg} *\right)$ present in planetary samples with near-solar $\mathrm{Al} / \mathrm{Mg}$ ratios. However, this heterogeneity can have two possible origins: (1) heterogeneous distribution of $\mathrm{Mg}$ isotopes or (2) variations in the ${ }^{26} \mathrm{Al} /{ }^{27} \mathrm{Al}$ ratio within the solar nebula. The determination of $\mathrm{Mg}$ isotope anomalies attributable to incomplete nucleosynthetic source mixing is hindered by the input of ${ }^{26} \mathrm{Mg}$ from ${ }^{26} \mathrm{Al}$ radioactive decay, since the contribution of radiogenic ${ }^{26} \mathrm{Mg}$ obscures the interpretation of nucleosynthetic isotope effects.

The investigation of correlations in isotopic patterns in elements with related nucleosynthetic sources has been used to quantify possible heterogeneities in the early solar system (e.g., Moynier et al. 2010). Volatility differences may lead to a decoupling of elements with the same nucleosynthetic source. The chance of this thermal decoupling is minimized in elements with similar volatilities in the solar nebula, characterized by the $50 \%$ condensation temperature (denoted $T_{c}$ ). Therefore, the comparable volatilities of $\mathrm{Si}$ and $\mathrm{Mg}\left(T_{c} \mathrm{Si}=1310 \mathrm{~K} ; T_{c} \mathrm{Mg}=\right.$ $1336 \mathrm{~K}$; Lodders 2003) make $\mathrm{Si}$ isotopes well suited to constrain possible $\mathrm{Mg}$ isotope heterogeneity in the solar nebula.

Figure 2 shows $\mathrm{Si}$ and $\mathrm{Mg}$ isotope mass fractions as a function of interior mass in a 25 solar mass supernova ejecta of the stellar model s25a37j of Rauscher et al. (2002). Explosive carbon burning occurring in the outer layers of the supernova produces large excesses in ${ }^{29} \mathrm{Si}$ and ${ }^{30} \mathrm{Si}$, while ${ }^{28} \mathrm{Si}$ is mainly produced by oxygen burning in more interior regions. The pattern of $\mathrm{Mg}$ isotope production is different; ${ }^{24} \mathrm{Mg},{ }^{25} \mathrm{Mg}$, and ${ }^{26} \mathrm{Mg}$ are all co-produced during carbon burning. The outer regions of the supernova are only slightly enriched in the neutron-rich isotopes ${ }^{25} \mathrm{Mg}$ and ${ }^{26} \mathrm{Mg}$, and, as a result, the magnitude of the heavy-isotope overabundance is smaller for $\mathrm{Mg}$ than for $\mathrm{Si}$. Consequently, any excess in neutron-rich $\mathrm{Mg}$ isotopes would be associated with a much larger effect on neutron-rich Si isotopes. Following this logic, Molini-Velsko et al. (1984) suggested that the calculated $\mathrm{Si}$ isotopic effect would be 75 times larger than the $\mathrm{Mg}$ isotopic effect. The $\mathrm{Si}$ isotopic homogeneity of solar system material as indicated by this study (at $\pm 15 \mathrm{ppm}$ ) implies that $\mathrm{Mg}$ isotopes were also well mixed (at least at a $15 \mathrm{ppm}$ level). Therefore, the heterogeneous distribution of ${ }^{26} \mathrm{Mg}$ excesses across solar system materials (e.g., Larsen et al. 2011) must reflect heterogeneous distribution of the $\mathrm{Al}$ isotope ratio.

The case of the small anomalies $\left(\varepsilon^{29} \mathrm{Si}=0.18 \pm 0.10,2\right.$ se, $n=5$ ) found in the angrites is puzzling. The mechanism by which a group of differentiated meteorites could preserve isotopic anomalies while all chondritic meteorites are isotopically homogenized is unclear. Use of the wrong power law for data normalization could introduce artificial isotopic effects in samples for which large mass dependent isotopic fractionation occurred due to a non-equilibrium (kinetic) process (e.g., evaporation). In this case, the fractionation would follow a Rayleigh distillation, and the generalized power law with exponent $n=$ $-1 / 2$ would be the appropriate normalization scheme instead of the exponential case (generalized power law with exponent $n=0$ ) used here (Maréchal et al. 1999). In other words, the $\mathrm{Si}$ isotopic fractionation between state a and state $\mathrm{b}$ can be expressed in terms of two fractionation factors $\alpha$ (Young \& Galy 2004) such that

$$
\alpha_{x / 28}=\frac{\left({ }^{x} \mathrm{Si} /{ }^{28} \mathrm{Si}\right)_{\mathrm{a}}}{\left({ }^{x} \mathrm{Si} /{ }^{28} \mathrm{Si}\right)_{\mathrm{b}}}
$$

where $x=29$ or 30 , which are related by the expression

$$
\alpha_{29 / 28}=\alpha_{30 / 28}^{\beta}
$$

where the exponent is expressed as

$$
\beta=\frac{\left(1 / m_{1}-1 / m_{2}\right)}{\left(1 / m_{1}-1 / m_{3}\right)}
$$


in the case of equilibrium fractionation and

$$
\beta=\frac{\ln \left(m_{1} / m_{2}\right)}{\ln \left(m_{1} / m_{3}\right)}
$$

in the case of kinetic fractionation, and $m_{1}, m_{2}$, and $m_{3}$ are the masses of ${ }^{28} \mathrm{Si},{ }^{29} \mathrm{Si}$, and ${ }^{30} \mathrm{Si}$, respectively. Numerically, the difference between equilibrium fractionation and kinetic fractionation changes the value of the exponent $\beta$ in Equation (3) from 0.5178 (equilibrium fractionation, Equation (4)) to 0.5092 (kinetic fractionation, Equation (5)).

The magnitude of the error introduced on $\varepsilon^{29} \mathrm{Si}$ through the use of an inappropriate normalization correction can be calculated from Equation (6), adapted from the example given for ${ }^{60} \mathrm{Ni}$ by Tang \& Dauphas (2012),

$$
\varepsilon^{29} \mathrm{Si} \approx 5(n-k) \frac{(29-28)(29-30)}{28} F \approx-0.09 F
$$

where $n$ and $k$ are the power law exponents for Rayleigh or exponential isotopic fractionation, respectively (i.e., $n=-1 / 2$, $k=0$ ), and $F$ is the isotopic fractionation in permil $\mathrm{amu}^{-1}$. To account for the observed $\varepsilon^{29} \mathrm{Si}$ for the angrite average, a $\mathrm{Si}$ isotopic fractionation between 1 and 2 permil $\mathrm{amu}^{-1}$ (i.e., $10-20 \varepsilon$-units on the ${ }^{29} \mathrm{Si} /{ }^{28} \mathrm{Si}$ ratio) would be required. This exceeds by more than an order of magnitude the mass-dependent fractionation measured to date in bulk meteorite materials (which is currently less than 0.1 permil $\mathrm{amu}^{-1}$, or $1 \varepsilon$-unit on ${ }^{29} \mathrm{Si} /{ }^{28} \mathrm{Si}$ ). Therefore, the use of an inappropriate normalization scheme is an unlikely explanation to fully account for the $\mathrm{Si}$ isotopic anomalies in the angrite data. This suggests that angrites have preserved some small Si isotopic heterogeneity, the reasons for which are still unknown. These ${ }^{29} \mathrm{Si}$ excesses may have implications for the distribution of $\mathrm{Mg}$ isotopes. Unfortunately, there is only one sample (D'Orbigny; Schiller et al. 2010) for which both $\mathrm{Si}$ isotopic data and the initial $\delta^{26} \mathrm{Mg}^{*}$ value are available, so it is impossible to interpret both isotopic systems at this stage. However, it has been noted that angrites have high initial $\delta^{26} \mathrm{Mg} *$ compared to other differentiated meteorites (Schiller et al. 2010), which could suggest some possible Mg isotope heterogeneity in line with ${ }^{29} \mathrm{Si}$ excesses.

\section{CONCLUSION}

After correction for mass-dependent isotopic fractionation, the $\mathrm{Si}$ isotopic composition of most meteorite groups is not resolvable from terrestrial composition within the current level of analytical precision. The lack of $\mathrm{Si}$ isotopic anomalies at the bulk-rock scale in solar system materials indicates homogenization of material in the solar nebula prior to planetary accretion. This constrains the possible heterogeneity of $\mathrm{Mg}$ isotopes to less than $15 \mathrm{ppm}$.

We thank Julien Foriel for maintaining the MC-ICPMS and the clean lab facilities at Washington University in St. Louis and Francois-Regis Orthous-Daunay for assistance with the download of the stellar model data. This work was made possible by the provision of samples from Timothy McCoy (US National Museum of Natural History, Smithsonian Institution, Washington, DC), Alex Bevan (Western Australian Museum, Perth), Franz Brandstatter (Naturhistorisches Museum, Vienna), James Holstein, Clarita Nunez and Philip Heck (The Field Museum, Chicago), Meenakshi Wadhwa (Arizona State University, Tempe), Cecilia Satterwhite (NASA Johnson Space Center, Houston), the Comite de Gestion (Museum Nationale dHistoire Naturelle, Paris), and Guy Consolmagno (Vatican). This work was supported by NASA EXO (NNX12AD88G) and COSMO (NNX12AH70G) grants and a chaire d'excellence from the Idex Sorbonne Paris Cité to F.M. E.P. and P.S. thank the McDonnell Center for Space Sciences for funding.

\section{REFERENCES}

Birck, J.-L. 2004, in Geochemistry of Non-Traditional Stable Isotopes, ed. C. M. Johnson, B. L. Beard, \& F. Albarède (Washington, DC: Mineralogical Society of America), 26

Bouvier, A., Blichert-Toft, J., Moynier, F., Vervoort, J. D., \& Albarède, F. 2007, GeCoA, 71, 1583

Bouvier, A., \& Wadhwa, M. 2010, NatGe, 3, 637

Clayton, R. N. 1993, AREPS, 21, 115

Clayton, R. N. 2002, Natur, 415, 860

Dauphas, N., Cook, D. L., Sacarabany, A., et al. 2008, ApJ, 686, 560

Fitoussi, C., \& Bourdon, B. 2012, Sci, 335, 1477

Georg, R. B., Reynolds, B. C., Frank, M., \& Halliday, A. N. 2006, ChGeo, 235, 95

Hofmann, A. W. 1997, Natur, 385, 219

Jacobsen, B., Yin, Q. Z., Moynier, F., et al. 2008, E\&PSL, 272, 353

Larsen, K. K., Trinquier, A., Paton, C., et al. 2011, ApJL, 735, L37

Lewis, K. M., Lugaro, M., Gibson, B. K., \& Pilkington, K. 2013, ApJL, 768, L19

Lodders, K. 2003, ApJ, 591, 1220

Lodders, K., \& Amari, S. 2005, Chem. Erde, 65, 93

Lyons, J. R., \& Young, E. D. 2005, Natur, 435, 317

Maréchal, C., Télouk, P., \& Albarède, F. 1999, ChGeo, 156, 251

Molini-Velsko, C., Mayeda, T. K., \& Clayton, R. N. 1984, Metic, 19, 273

Molini-Velsko, C., Mayeda, T. K., \& Clayton, R. N. 1986, GeCoA, 50, 2719

Moynier, F., Dauphas, N., \& Podosek, F. A. 2009, ApJL, 700, L92

Moynier, F., Day, J. M. D., Okui, W., et al. 2012, ApJ, 758, 45

Moynier, F., Fujii, T., Brennecka, G. A., \& Nielsen, S. G. 2013, CRGeo, 345,150

Moynier, F., Simon, J. I., Podosek, F. A., et al. 2010, ApJL, 718, L7

Pringle, E. A., Savage, P. S., Badro, J., Barrat, J.-A., \& Moynier, F. 2013, E\&PSL, 373, 75

Rai, V. K., Jackson, T. L., \& Thiemens, M. H. 2005, Sci, 309, 1062

Rai, V. K., \& Thiemens, M. H. 2007, GeCoA, 71, 1341

Rauscher, T., Heger, A., Hoffman, R. D., \& Woosley, S. E. 2002, ApJ, 576, 323

Savage, P. S., \& Moynier, F. 2013, E\&PSL, 361, 487

Schiller, M., Baker, J. A., \& Bizzarro, M. 2010, GeCoA, 74, 4844

Simon, J. I., DePaolo, D. J., \& Moynier, F. 2009, ApJ, 702, 707

Tang, H., \& Dauphas, N. 2012, E\&PSL, 359, 248

Thiemens, M. H. 1999, Sci, 283, 341

Timmes, F. X., \& Clayton, D. D. 1996, ApJ, 472, 723

Villeneuve, J., Chaussidon, M., \& Libourel, G. 2009, Sci, 325, 985

Wang, K., Moynier, F., Podosek, F., \& Foriel, J. 2011, ApJL, 739, L58

Warren, P. 2011, E\&PSL, 311, 93

Young, E. D., \& Galy, A. 2004, in Geochemistry of Non-Traditional Stable Isotopes, ed. C. M. Johnson, B. Beard, \& F. Albarède (Washington, DC: Mineralogical Society of America), 197

Yurimoto, H., \& Kuramoto, K. 2004, Sci, 305, 1763

Zinner, E., Nittler, L. R., Gallino, R., et al. 2006, ApJ, 650, 350 